\title{
Is Laparoscopic Appendectomy a Safe Procedure? A Single Surgeon Experience at a University Hospital
}

\author{
Faisal M. Al-Mashat, FRCS (I \& Ed), FACS \\ Department of Surgery, Faculty of Medicine, \\ King Abdulaziz University, Jeddah Saudi Arabia \\ falmashat@yahoo.com
}

\begin{abstract}
The aim of this retrospective study was to evaluate the safety and benefits of laparoscopic appendectomy performed by a single surgeon at a university hospital and compare the results with other similar studies. The medical records of 113 patients with suspected appendicitis who underwent laparoscopic appendectomy (January 2003 to December 2004) were analyzed for demographic information, clinical findings, laboratory / ultrasound results, intraoperative diagnosis, clinicopathologic correlation, complications, incidental findings, and operative time. A pelvic ultrasound was done for $36(31.8 \%)$ patients. All patients received prophylactic antibiotics and none had drain. All appendices were removed whether they were inflamed or not. Pregnant patients were excluded from this study. There were 60 males and 53 females; with mean age 24.05 years. The mean operative time was 62.21 minutes. Conversion to open appendectomy was done in $8(7.1 \%)$ patients. Post-operative complications occurred in 14 $(12.4 \%)$ patients. The appendix was inflamed in $102(90.26 \%)$ patients. The mean hospital stay was 2.35 days and there was no mortality. Laparoscopic appendectomy is a safe procedure with acceptable complications without mortality. It is advocated as the procedure of choice for patients with suspected appendicitis.
\end{abstract}

Keywords: Laparoscopic appendectomy.

\section{Introduction}

Appendectomy in the course of an acute appendicitis is one of the most frequently performed surgical procedures in general surgery.

Correspondence \& reprint request to: $\quad$ Dr. Faisal M.H. Al-Mashat

P.O. Box 143, Jeddah 21411, Saudi Arabia

Accepted for publication: 23 March 2009. Received: 12 November 2007. 
Laparoscopy is the gold standard approach in many surgical procedures: This consideration is still controversial as to appendectomy ${ }^{[1]}$. Complete exploration of the abdomen and pelvis; better localization of the appendix and diagnosis of unexpected conditions associated with and without appendicitis can be achieved through laparoscopy. Laparoscopy can reveal various diseases without appendicitis ${ }^{[1]}$. Studies have demonstrated the diagnostic and therapeutic advantages of the procedure and its positive impact on laparoscopic training. It has been shown to be advantageous over an open appendectomy. Laparoscopic appendectomy (LA) is a safe procedure, and that postoperative morbidity is comparable with that for a conventional operation. There is less postoperative pain and shorter recovery time after laparoscopic surgery than after the open procedure $^{[2,3]}$. A trend towards better physical activity was noted after the laparoscopic procedure ${ }^{[3]}$. The major merit of the procedure is the high diagnostic accuracy in appendicitis and non-appendicitis pelvic diseases especially in female patients during the reproductive period. Herein, we evaluated our results of LA and compared them with other studies.

\section{Patients and Methods}

From January 2003 to December 2004, 113 patients underwent LA. Their recorded data were based on age, sex, clinical presentations, temperature, white blood cell count, operative time, conversion rate, hospital stay, histopathology reports and complications.

All patients were presented to the emergency department with classical and/or clinical suspicions of acute appendicitis were included. Pregnancy was the only criterion for exclusion. Investigations included complete blood count (CBC) and ultrasound.

LA was performed under general anesthesia. The position of the patient, surgeon, assistant, nurse, anesthesiologist and the equipment is shown in Fig. 1. A standard technique was used for all patients. Pneumoperitoneum was established using a Verres needle at the umbilicus. A $45^{\circ}$ telescope is introduced through a $10 \mathrm{~mm}$ umbilical port. A $10 \mathrm{~mm}$ and a $5 \mathrm{~mm}$ ports were placed in the left lower and right lower quadrants, respectively. The patient was then changed to the 


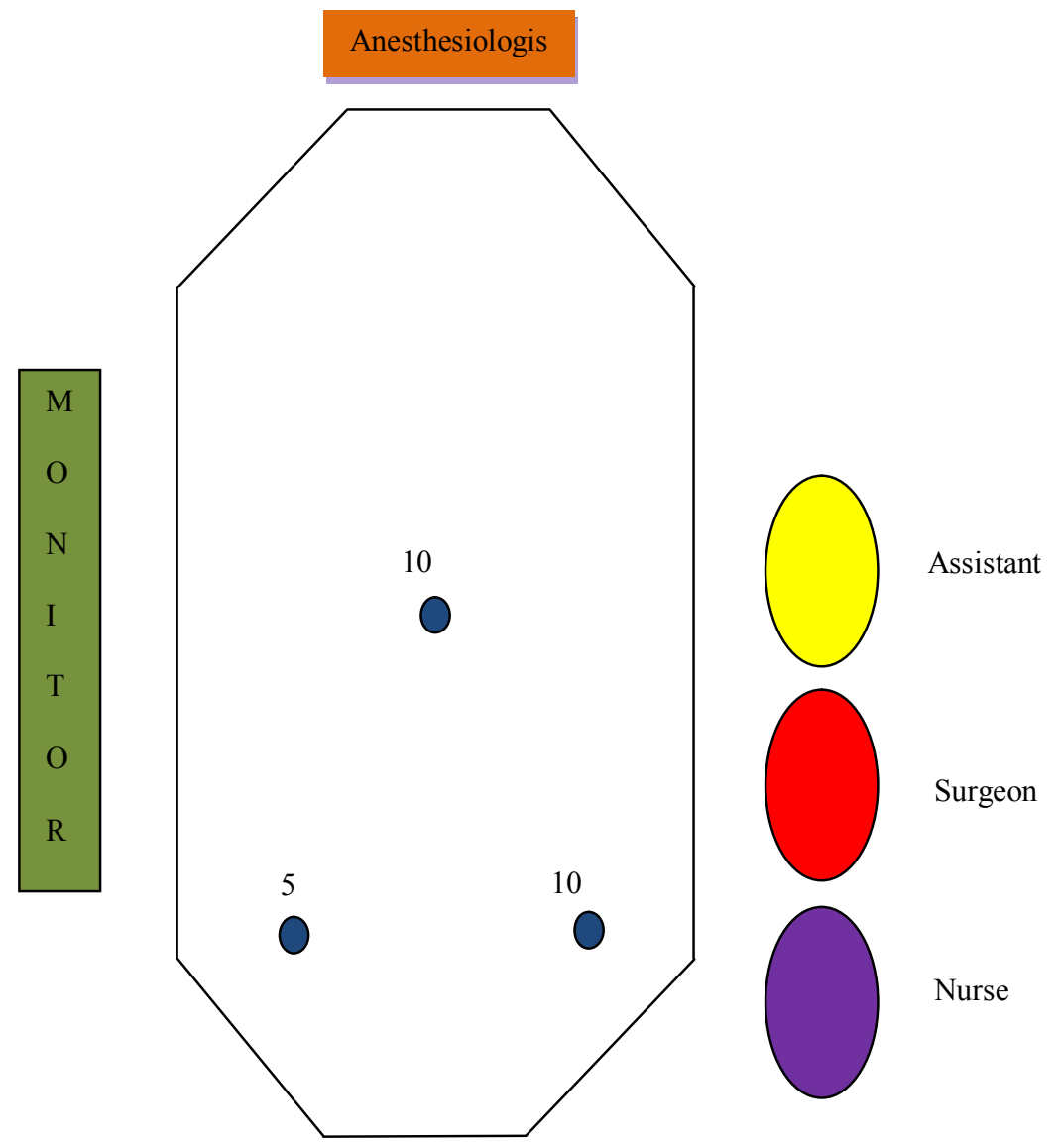

Fig. 1. Operating room (OR) arrangement in LA.

Trendelenburg position: an elevation to the right side of the operating table. After the appendix was located, it was then grasped to pull along its body. The meso-appendix is divided using endoclips or bipolar diathermy and the appendix was ligated at the base using PDS 2/0 endoloops. Two endoloops were placed proximal and one distal to the appendicular stump. The divided appendix was delivered through the left lower quadrant $10 \mathrm{~mm}$ port. The stump was irrigated with povidoneiodine (Fig. 2). Any remaining fluids or pus were thoroughly suctioned. No drain was fixed. Patients who required conversion to open appendectomy (OA), a transverse muscle-splitting incision was made in the right lower quadrant. All patients received a single dose of 
prophylactic antibiotics intravenously with induction of anesthesia, usually a second generation cephalosporins.

All patients were reviewed in the outpatient clinic 2 and 4 weeks after discharge from the hospital.
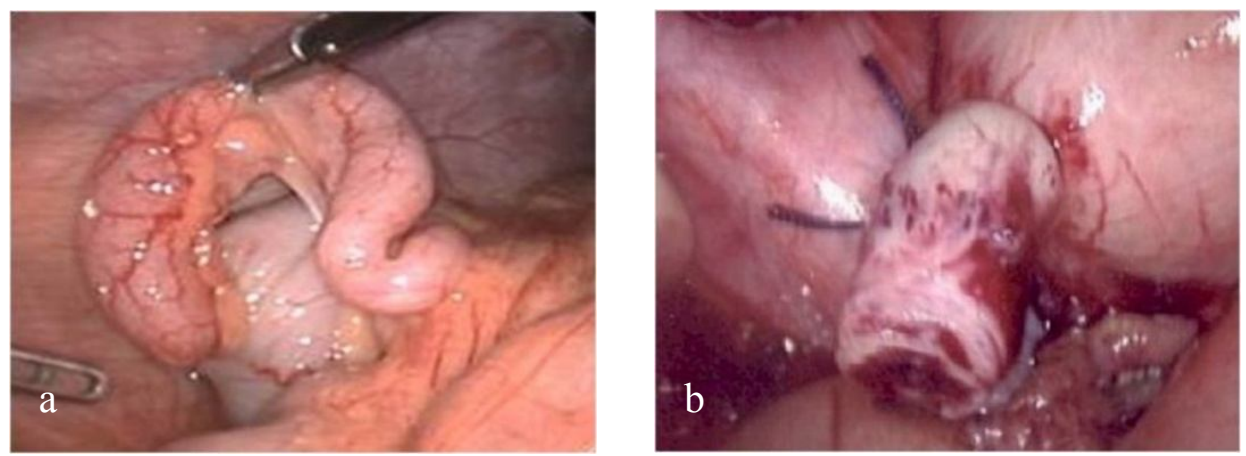

Fig. 2. Laparoscopy showing an inflamed appendix grasped with forceps (a), and the stump with endoloop (b).

\section{Results}

The age of the patients ranged from 7 years to 51 years (mean, 24.05 years), with 60 male $(53.1 \%)$ and 53 female $(46.9 \%)$ patients. The mean temperature was $37.42^{\circ} \mathrm{C}$ and the mean white blood count was $11.60\left(4-1110^{\wedge} \mathrm{g} / \mathrm{l}\right)$. A Pelvic US was performed for $36(31.8 \%)$ patients. Operative times were between 30 minutes to 140 minutes (mean, 62.21 minutes). There were no statistical differences in the mean operative time between the three groups (Table 1). This is due to the involvement of one laparoscopic surgeon in performing LA in this study. Eight (7.1\%) patients were converted to OA. The indications for conversion are outlined in Table 2. The conversion was aimed to avoid the risk of injuring the adjacent loops of bowel due to unclear anatomy or excessive dissection in an inflamed area. Post-operative complications occurred in $14(12.4 \%)$ patients. Wound infection was the most common complication and was observed in $8(7.1 \%)$ patients. Other complications were less commonly encountered (Table 3 ). Two patients developed abscesses, one pelvic drained rectally and the other one in right iliac fossa and drained percutaneously. The diagnosis of appendicitis was histologically confirmed for $102(90.26 \%)$ patients, while $11(9.73 \%)$ patients had normal appendix (Table 4). The underlying cause of the 
lower abdominal pain in patients with normal - looking appendix, was due to other pathological conditions, mainly gynecological (Table 5). A gynecological cause in normal appendix was found in 8 patients $(7.1 \%)$. The hospital stay ranged from 1 to 7 days (mean, 2.35 days). There were no deaths.

Table 1. Operative time in minutes.

\begin{tabular}{l|c|c}
\hline & Total & Mean \\
\hline $1^{\text {st }} 37$ patients & 2220 & 60 \\
\hline $2^{\text {nd }} 37$ patients & 2260 & 61.08 \\
\hline $3^{\text {rd }} 39$ patients & 2250 & 57.69 \\
\hline
\end{tabular}

Table 2. Criteria for conversion in LA.

\begin{tabular}{l|l|c}
\hline & & No. of Patients \\
\hline 1 & Difficult anatomy & 4 \\
\hline 2 & Appendicular mass & 3 \\
\hline 3 & Appendicular abscess & 1 \\
\hline
\end{tabular}

Table 3. Post operative complications of LA.

\begin{tabular}{c|l|c|c}
\hline & & No. of Patients & \% \\
\hline 1 & Wound infection & 8 & 7.10 \\
\hline 2 & Paralytic ileus & 4 & 3.50 \\
\hline 3 & Abscesses & 2 & 1.80 \\
\hline & & 14 & 12.40 \\
\hline
\end{tabular}

Table 4. Histopathology of appendices in LA.

\begin{tabular}{c|l|c|c}
\hline & \multicolumn{1}{|c|}{ Pathology } & No. of Patients & \% \\
\hline 1 & Catarrhal appendicitis & 81 & 71.70 \\
\hline 2 & Suppurative appendicitis & 21 & 18.60 \\
\hline 3 & Normal & 11 & 9.70 \\
\hline
\end{tabular}

Table 5. Associated conditions with normal - looking appendix.

\begin{tabular}{c|l|c}
\hline & \multicolumn{1}{|c}{ Pathology } & No. of Patients \\
\hline 1 & Pelvic inflammatory disease & 6 \\
\hline 2 & Mid cycle pain & 1 \\
\hline 3 & Ruptured ovarian follicle & 1 \\
\hline 4 & Unknown & 3 \\
\hline & Total & 11 \\
\hline
\end{tabular}




\section{Discussion}

Laparoscopy is safe for diagnostic and therapeutic purposes in patients with suspected acute appendicitis. It offers all the advantages of minimally invasive surgery with less pain, short hospital stay, early return of bowel function, and improved cosmesis. Several reports have evaluated the advantages and disadvantages of LA. LA does not offer significant benefits over OA in patients with acute appendicitis; with the exception of the esthetic aspect in women, disadvantages of longer operative time and more expensive ${ }^{[4]}$. The greatest benefits of the laparoscopic technique are that it causes less trauma, the diagnostic accuracy is better, and the cosmetic result is superior to that after a conventional operation ${ }^{[5]}$. Operative time, cost-effectiveness and complications remain major issues to be considered. In patients with suspected appendicitis, LA is gaining increasing acceptance primarily because it is associated with less postoperative pain, minimal hospitalization, and rapid convalescent times ${ }^{[6]}$. LA is now well accepted for the treatment of complicated and uncomplicated appendicitis in childre ${ }^{[7]}$. The reported mean operative time in various studies ranged from 28 minutes to 103.03 minutes $^{[4,8]}$. In situations where the anatomy is not clear or if there is a possibility of injuring adjacent structures, conversion to OA is mandatory. Conversion to OA is not regarded as a complication, but rather as a safe practice. A conversion rate from $0 \%$ to $39 \%$ have been established ${ }^{[1,6,9]}$. Hospital stay was evaluated by many studies and found to range from 2 days to 4.71 days ${ }^{[2,3]}$. Whether or not to remove a normal looking appendix during LA is still questionable. Laparoscopy has reduced the rate of histologically normal appendectomies due to intra-operative visualization of the appendix from $22.8 \%$ to $10.2 \%{ }^{[10]}$. A macroscopically normal-looking appendix can be left in place ${ }^{[9]}$. The reported incidence of grossly normal appendix during LA is $16 \%{ }^{[5]}$. The greater diagnostic accuracy of laparoscopy allowed the diagnosis of concurrent diseases in $12 \%{ }^{[11]}$. Corsale et al. was found that laparoscopy revealed various diseases without appendicitis in $11(17.7 \%)$ patients ${ }^{[1]}$. Similarly, among those patients without gross or microscopic evidence of appendicitis, or both gross and microscopic evidence, concurrent diseases were detected in $57.3 \%^{[11]}$. Post operative complications occur in $1.6 \%$ to $18.5 \%^{[11,12]}$. Post operative port-site infection in $0.0 \%$ to $8.5 \%$ following $\mathrm{LA}^{[6,13]}$. The risk for intra-abdominal abscess after LA is still a matter of debate. Earlier studies suggested an 
increased intra-abdominal abscess rates following LA, especially for perforated appendicitis. Currently, LA does not lead to more intraabdominal abscesses than the open technique; even for perforated appendicitis the laparoscopic technique can be used safely ${ }^{[14,15]}$. Therefore, LA for complicated appendicitis may not be contraindicated, even for perforated appendicitis ${ }^{[16]}$. The mortality of LA ranges from $0.3 \%$ to $0.4 \%{ }^{[9,11]}$.

In conclusion, LA is a safe and an effective procedure in acute appendicitis. Discovery of other intra-abdominal pathologies is accurate. Our results in terms of mean operative time, conversion to OA, mean hospital stay and complications without mortality are comparable to those of international series. LA should be considered as the first-line approach for all patients with appendicitis.

\section{Acknowledgment}

I would like to show appreciation to Mrs. Joy Almeda De Silva for her secretarial help.

\section{References}

[1] Corsale I, Buccianelli E, Sorce S, Aloise F, Bartolomei M, Mori P, Rigutini M, Veltroni A. [Appendicectomy: laparoscopic versus open treatment. A case survey]. Minerva Chir 2005; 60(1): 55-59.

[2] Milewczyk M, Michalik M, Ciesielski M. A prospective, randomized, unicenter study comparing laparoscopic, and open treatments of an acute appendicitis. Surg Endosc 2003; 17(7): 1023-1028. Epub 2003 May 6.

[3] Moberg AC, Berndsen F, Palmquist I, Petersson U, Resch T, Montgomery A. Randomized clinical trial of laparoscopic versus open appendectomy for confirmed appendicitis. Br J Surg 2005; 92(3): 298-304.

[4] Rivera Díaz EM. [Comparative evaluation of the surgical treatment of acute appendicitis: open appendicetomy versus laparoscopic appendectomy in the national hospital hospital Carlos a. Seguin e. Essalud] Rev Gastroenterol Peru 2002; 22(4): 287-296.

[5] Moberg AC, Montgomery A. Appendicitis: laparoscopic versus conventional operation: a study and review of the literature. Surg Laparosc Endosc 1997; 7(6): 459-463.

[6] Palesty JA, Wang XJ, Rutland RC, Leighton J, Dudrick SJ, Benbrahim A. Fifty-five consecutive laparoscopic appendectomy procedures without conversion. JSLS 2004; 8(2): 141-145.

[7] Pham VA, Pham HN, Ho TH. Laparoscopic appendectomy: an efficacious alternative for complicated appendicitis in children. Eur J Pediatr Surg 2009; 19(3):157-159.

[8] Utpal D. Laparoscopic versus open appendectomy in West Bengal, India. Chin J Dig Dis 2005; 6(4): 165-169. 
[9] Moberg AC, Ahlberg G, Leijonmarck CE, Montgomery A, Reiertsen O, Rosseland AR, Stoerksson R. Diagnostic laparoscopy in 1043 patients with suspected acute appendicitis. Eur J Surg 1998; 164(11): 833-841.

[10] Al Hilli Z, Prichard RS, Roche-Nagle G, Leader M, McNamara DA, Deasy J. Emergency appendectomy in the era of laparoscopy: a one-year audit. Ir J Med Sci 2009 Apr 7.

[11] Agresta F, De Simone P, Michelet I, Bedin N. Laparoscopic appendectomy: why it should be done. JSLS 2003; 7(4): 347-352.

[12] Katkhouda N, Mason RJ, Towfigh S, Gevorgyan A, Essani R. Laparoscopic versus open appendectomy: a prospective randomized double-blind study. Ann Surg 2005; 242(3): 439450.

[13] Patel SC, Jumba GF, Akmal S. Laparoscopic appendectomy at the Aga Khan Hospital, Nairobi. East Afr Med J 2003; 80(9): 447-451.

[14] Kouwenhoven EA, Repelaer van Driel OJ, van Erp WF. Fear for the intraabdominal abscess after laparoscopic appendectomy: not realistic. Surg Endosc 2005; 19(7): 923-926. Epub 2005 May 12.

[15] Garg CP, Vaidya BB, Chengalath MM. Efficacy of laparoscopy in complicated appendicitis. Int J Surg 2009 Apr 23.

[16] Katkhouda N, Friedlander MH, Grant SW, Achanta KK, Essani R, Paik P, Velmahos G, Campos G, Mason R, Mavor E. Intraabdominal abscess rate after laparoscopic appendectomy. Am J Surg 2000; 180(6): 456-461. 


\section{هل إز الة الز ائدة الدودية بالمنظار طريقة مأمونة؟ خبرة جر اح مناظير في مسنتفى جامعى}

\section{فيصل محمد المشاط}

قسم الجراحة ، كلية الطب ، جامعة الملك عبدالعزيز جدة - المدلكة العربية السعودية

المستخلص. تمت مر اجعة ملفات المرضى المصابين، أو من يشتبه

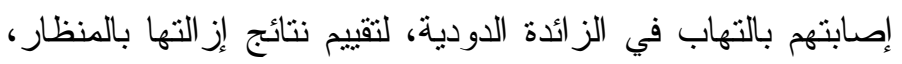

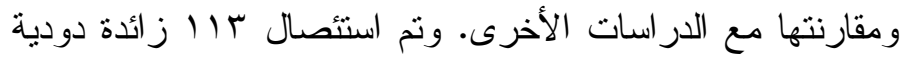

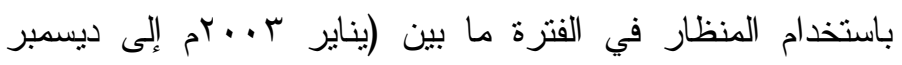

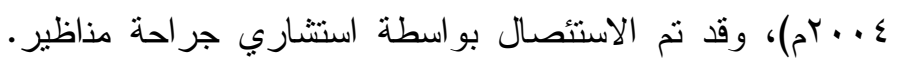

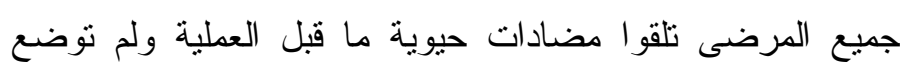

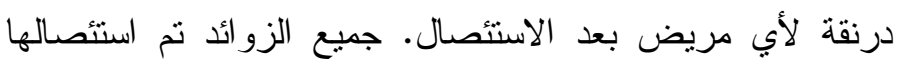

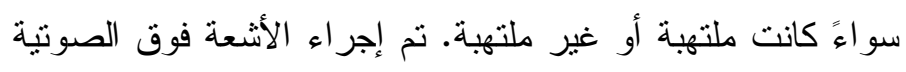

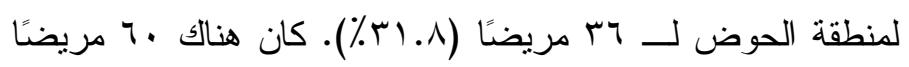

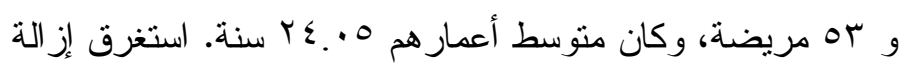

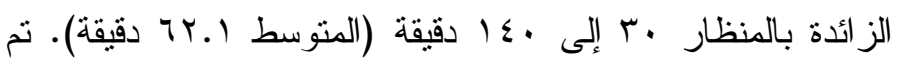

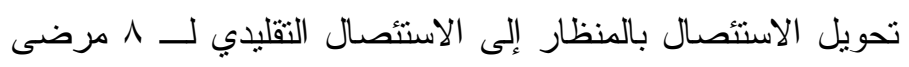

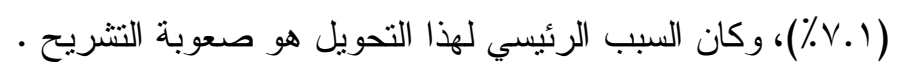

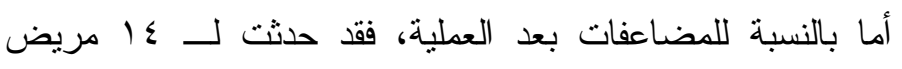

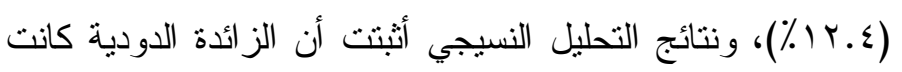

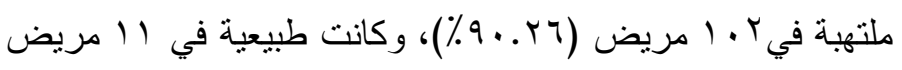

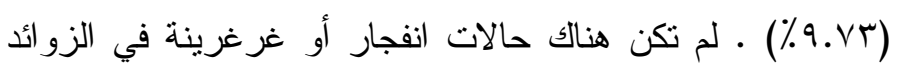
التي تم استئصالها ولم تكن هناك ولك وفيات. المفتاح: إز الة الز ائدة الدودية بالمنظار . 